\title{
THE BACHELOR OF BIOCHEMISTRY IN BRAZIL
}

\author{
Cordeiro, H.G ${ }^{1}$, Dias, G.G. ${ }^{1}$, Pompeu, D.G. $^{1}$, Torres, B. ${ }^{2}$, Granjeiro, P.A. ${ }^{1}$ \\ ${ }^{1}$ Curso de Bioquímica, CCO-UFSJ, MG, Brazil; ${ }^{2}$ Departamento de Bioquímica, \\ Instituto de Química, USP, SP, Brazil
}

INTRODUCTION: The economic and social development of Brazil in the last decade has contributed to the installation of new graduate and undergraduate programs, as are the case with bachelor degrees in Biochemistry at UFV, UFSJ and UEM. These graduates are prepared to work in industry, research institutes and universities in areas of knowledge involving Biochemistry and Molecular Biology. This is happening in developed countries since the first half of the last century, surprising and late is the implementation of bachelor of Biochemistry in Brazil. OBJECTIVES: The aim of this study was to perform a comparative analysis of the Bachelor in Biochemistry in Brazil from the perspective of the main difficulties of implementing and courses maintenance. MATERIAL AND METHODS: This is a descriptive research with a qualitative approach. Interviews were conducted with undergraduate students, graduates, professors, staff and managers from bachelor degrees in Biochemistry at UFV, UFSJ and UEM. The sampling procedure was non probabilistic for judgment (choice of the subjects involved and interested in the course of biochemistry) to undergraduate students, graduates, professors and staff and non probabilistic for convenience to managers. The qualitative assessment to depict the representative keywords was performed using words cloud by WordleTM. RESULTS: The study included 5 managers, 24 professors, 12 staff, 25 undergraduate students, 5 graduates. For the students the main reason for the course selection should be scientific vocation and affinity with chemistry and biology; most cited positive parameters were faculty and great structure, practical classes and broad playing field; most cited negatives were high mandatory disciplines, little student free time and lack of sophisticated equipment. Despite the conception of the programs have happened in different contexts and regions we noted similarities deficiencies and distresses. CONCLUSION: Difficulties must be overcome for all courses are structural adjustments in program and physical installation.

Keywords: Bachelor, Biochemistry, Brazil.

Sponsor: UFSJ 